\title{
The extent to which cancer patients trust in cancer-related online information: a systematic review
}

\author{
Lukas Lange ${ }^{\text {Corresp., } 1}$, Mona Leandra Peikert ${ }^{1}$, Christiane Bleich $^{1}$, Holger Schulz ${ }^{1}$ \\ ${ }^{1}$ Department of Medical Psychology, University Medical Center Hamburg-Eppendorf, Hamburg, Hamburg, Germany \\ Corresponding Author: Lukas Lange \\ Email address: lu.lange@uke.de
}

Background. The use of the internet to satisfy information needs is widespread among cancer patients. Patients' decisions regarding whether to act upon the information they find strongly depend on the trustworthiness of the information and the medium. Patients who are younger, more highly educated and female are more likely to trust online information. The objectives of this systematic review were to examine the extent to which cancer patients trust in cancer-related online information, internet websites as a source of cancer-related information or the internet as a medium of cancer information.

Methods. A systematic review was conducted using five databases (PROSPERO registration number: CRD42017070190). Studies of any kind were included if they measured cancer patients' trust in online health information. Study quality was assessed using the Research Triangle Institute (RTI) item bank. A narrative synthesis was undertaken to examine the included studies.

Results. Of the 7314 citations obtained by the search, 7 cross-sectional studies were included in the synthesis. A total of 1054 patients reported having some or a great deal of trust in online cancer information; 154 patients reported moderately trusting such information; and 833 patients reported having no or little trust in online cancer information, internet websites as a source of cancer-related information or the internet as a medium of cancer-related information. Two of the seven studies reported between group comparisons for the above-stated patient characteristics. The methodological quality of the included studies was diverse.

Conclusion. The results of the included studies indicates that approximately half of cancer patients appear to trust cancer-specific online information, internet websites as a source of cancer-related information or the internet as an information medium. However, the small number of included studies, high heterogeneity of participants, methods and outcomes calls for further systematic research. It is important to understand that cancer patients do and will increasingly use trusted cancer information websites to search for information concerning their disease. Therefore, physicians and other health care providers should provide more support and advice to these patients. 


\section{The extent to which cancer patients trust in cancer-related}

\section{2 online information: a systematic review}

4 Lukas Lange ${ }^{1}$, Mona Leandra Peikert ${ }^{1}$, Christiane Bleich $^{1}$, Holger Schulz ${ }^{1}$ 5

$6{ }^{1}$ Department of Medical Psychology, University Medical Center Hamburg Eppendorf, Hamburg, 7 Hamburg, Germany

9 Corresponding author:

10 Lukas Lange ${ }^{1}$

11 Martinistraße 52, Hamburg, Hamburg, Germany

12 Email address: lu.lange@uke.de

\section{Abstract}

15 Background. The use of the internet to satisfy information needs is widespread among cancer

16 patients. Patients' decisions regarding whether to act upon the information they find strongly

17 depend on the trustworthiness of the information and the medium. Patients who are younger,

18 more highly educated and female are more likely to trust online information. The objectives of

19 this systematic review were to examine the extent to which cancer patients trust in cancer-related

20 online information, internet websites as a source of cancer-related information or the internet as a

21 medium of cancer information. 
22 Methods. A systematic review was conducted using five databases (PROSPERO registration

23 number: CRD42017070190). Studies of any kind were included if they measured cancer patients'

24 trust in online health information. Study quality was assessed using the Research Triangle

25 Institute (RTI) item bank. A narrative synthesis was undertaken to examine the included studies.

26 Results. Of the 7314 citations obtained by the search, 7 cross-sectional studies were included in

27 the synthesis. A total of 1054 patients reported having some or a great deal of trust in online

28 cancer information; 154 patients reported moderately trusting such information; and 833 patients

29 reported having no or little trust in online cancer information, internet websites as a source of

30 cancer-related information or the internet as a medium of cancer-related information. Two of the

31 seven studies reported between group comparisons for the above-stated patient characteristics.

32 The methodological quality of the included studies was diverse.

33 Conclusion. The results of the included studies indicates that approximately half of cancer

34 patients appear to trust cancer-specific online information, internet websites as a source of

35 cancer-related information or the internet as an information medium. However, the small number

36 of included studies, high heterogeneity of participants, methods and outcomes calls for further

37 systematic research. It is important to understand that cancer patients do and will increasingly

38 use trusted cancer information websites to search for information concerning their disease.

39 Therefore, physicians and other health care providers should provide more support and advice to 40 these patients.

\section{Introduction}

42 Information needs are among the most prevalent unmet supportive care needs of cancer patients

43 throughout their cancer journey (Harrison et al. 2009). The majority of cancer patients want to

44 have all available information concerning their illness and treatment (Davies et al. 2008; Jenkins 
45 et al. 2001; Newnham et al. 2006). The internet allows cancer patients to fulfill their needs for

46 information regarding their diagnosis, prognosis or likelihood of cure, disease stage, and

47 treatment options or the side effects of the treatment in question (Castleton et al. 2011; Maddock

48 et al. 2011; Tariman et al. 2014). Internet utilization is widespread in advanced economies: $89 \%$

49 of the US population and $80 \%$ of the European population reported using the internet at least

50 occasionally (Poushter 2016). Compared with other information sources, the internet has the

51 unique advantage of convenience. Cancer patients can anonymously access the internet anytime

52 from almost anywhere (Maddock et al. 2011; Ziebland et al. 2004).

53 The prevalence of cancer patients who used the internet to look for cancer-related information in

54 a Dutch sample, two American samples and a Swedish sample ranged from $60 \%$ to $75 \%$

55 (Castleton et al. 2011; Mattsson et al. 2017; Mayer et al. 2007; van de Poll-Franse \& van

56 Eenbergen 2008), and the prevalence appears to be increasing (Finney Rutten et al. 2016).

57 There are various motivational reasons for cancer patients to search for cancer information on the

58 internet. Patients reported going online because they wanted to develop questions to discuss with

59 their physician, verify information given by their physician, or seek alternative treatments

60 (Castleton et al. 2011) and because they felt that the amount of information they received from

61 their physician was insufficient (Chen \& Siu 2001).

62 Information obtained from the internet can impact clinical care in different ways. Cancer-related

63 online information can change patients' choice of treatment, their choice of physician, and their

64 decisions regarding enrollment in a clinical trial (Castleton et al. 2011). Most cancer patients do

65 not believe that online information searching negatively affects the doctor-patient relationship

66 (Newnham et al. 2006). However, some cancer patients are careful about discussing online

67 information with their physicians. These patients worry that their online searches might have a 
68 negative influence on their relationship and might cause physicians to treat them as a problematic

69 patient (Broom 2005; Chiu 2011). Additionally, some oncologists admit to having some

70 difficulty discussing internet-based information with their patients. These oncologists are more

71 likely to report that information obtained from the internet confuses patients (Helft et al. 2003).

72 Cancer patients who search the internet for cancer-related information tend to be younger and

73 more highly educated than those who do not (Castleton et al. 2011; Mattsson et al. 2017;

74 Shahrokni et al. 2014), and they are more likely to have a partner (Mattsson et al. 2017). Both

75 age and education are also associated with higher unmet information needs among cancer

76 patients (Sondergaard et al. 2013). One study found that female gender was a factor associated

77 with seeking cancer-related information (Mayer et al. 2007), while another study did not

78 (Castleton et al. 2011). A higher likelihood of internet use was further associated with better self-

79 reported health among cancer survivors (Chou et al. 2011).

80 The quality of the cancer-related information that can be accessed on the internet is highly

81 variable. Several studies used the DISCERN scale, a validated instrument developed to help

82 consumers evaluate the quality of health-related information on treatment choices for a specific

83 health problem (Charnock et al. 1999), to evaluate the quality of websites that provide cancer-

84 related information. The websites were generated by typing cancer-related search terms (i.e.,

85 'cancer', 'cancer therapy', 'breast cancer' or 'colon cancer') in popular search engines, such as

86 Google or Bing and focusing mainly on the first search results (Borgmann et al. 2016; Bruce et

87 al. 2015; Hargrave et al. 2006; Liebl et al. 2015; Nghiem et al. 2016; Ni Riordain \& McCreary

88 2009; Wasserman et al. 2014), as most users will not proceed any further (Eysenbach \& Köhler

89 2002). The evaluated websites' information was often incomplete and did not provide all of the

90 details necessary to allow cancer patients to make well-informed decisions (Al-Bahrani \& Plusa 
91 2004; Borgmann et al. 2016; Bruce et al. 2015; Hargrave et al. 2006; Liebl et al. 2015; Nghiem

92 et al. 2016; Ni Riordain \& McCreary 2009; Wasserman et al. 2014). However, the results of two

93 studies indicate a difference between the information quality of different website types. The

94 quality of websites from nonprofit organizations or the government was higher than the quality

95 of websites from the medical practices or commercial health information websites (Liebl et al.

96 2015; Nghiem et al. 2016).

97 Few studies have investigated which types of websites cancer patients visit to satisfy their

98 information needs. Nonetheless, cancer patients consider health information websites to be a

99 more valuable source of health information than forums or blogs (Mattsson et al. 2017). These

100 patients report preferring to obtain reliable information regarding cancer from websites of their

101 oncologist, hospital, or cancer society and are less likely to access websites with a profit interest.

102 However, the same patients mostly accessed websites that were financed and created by

103 pharmaceutic industries (van de Poll-Franse \& van Eenbergen 2008), which might promote their

104 own interests and can be of lower quality than nonprofit websites (Liebl et al. 2015).

105 Additionally, studies have revealed that health seekers do not consistently check the source and

106 date of the health information they found online (Eysenbach \& Köhler 2002; Fox 2006).

107 The varying quality of the cancer-related information available online presents cancer patients

108 with significant challenges in evaluating and selecting reliable online information sources and,

109 more specifically, in assessing the credibility and trustworthiness of these sources. Trust is an

110 important factor associated with the intention to use information found on a website (Dutton \&

111 Shepherd 2006; Lemire et al. 2008). People who trust in online health information become

112 motivated to participate in various online health-related activities that meet their informational

113 and emotional needs (Fisher et al. 2008). 
114 The decision whether to trust a cancer-related online information can be a complex one as

115 information-searching skills, prior experiences with the source and medium of the information,

116 and characteristics of the source may influence the cancer patient's decision. There are different

117 levels (individual, interpersonal, relational and societal) of trust that have been studied in the

118 literature. The interpersonal level appears to be the appropriate level for determining trust in

119 online information, as information is provided by an author (trustee) and communicated over a

120 certain channel (the internet) to a receiver (trustor) (Kelton et al. 2008). A definition of trust that

121 is often used at this level is that: "The willingness of a party to be vulnerable to the actions of

122 another party based on the expectation that the other will perform a particular action important to

123 the trustor, irrespective of the ability to monitor or control that other party" (Mayer et al. 1995).

124 The terms trust and credibility are often used interchangeably. However, credibility can be

125 described as perceived information quality, or the evaluation of information quality by a user

126 (Fogg \& Tseng 1999). After evaluating the credibility of information, a reader may decide

127 whether to trust or not trust it. The credibility evaluation process in online environments can be

128 explained by a dual processing model (Metzger 2007) or the 3S-model (where the three "Ss"

129 stand for semantics, surface, and source features of information) (Lucassen \& Schraagen 2011).

130 The dual processing model states that the decision whether a heuristic (peripheral) or systematic

131 (central) evaluation is performed is decided by the users' motivation and ability. The users'

132 motivation results from the consequence of receiving inferior, unreliable or inaccurate

133 information online (Metzger 2007). We prefer the 3S-model, because we believe that due to

134 existential concerns and their need for hope, cancer patients are a vulnerable population (Davey

135 et al. 2003) and therefore would be highly motivated. The 3S-model asserts that the most direct

136 strategy for evaluating credibility is to search for semantic cues (factual accuracy, neutrality or 
137 completeness of the information) in the information (Lucassen \& Schraagen 2011). However,

138 cancer patients usually search for information that is new to them and thus do not always have

139 the necessary expertise to evaluate the semantics of the information and consequently revert to

140 surface cues (writing style, text length or number of references) (Lucassen \& Schraagen 2011).

141 Systematic and heuristic processing are thus both used within a single search process.

142 Additionally, trust in online information is influenced by trust in its source (website), which in

143 turn is influenced by trust in the medium (internet) of this source and a general propensity to

144 trust (Lucassen et al. 2013). Users with low trust in the source (website) cannot distinguish

145 between high quality and inferior information (Lucassen \& Schraagen 2012). Trust in the

146 internet is largely affected by prior experience with this medium (Dutton \& Shepherd 2006). In

147 this study, we are interested in cancer patients' trust in the cancer-related information online,

148 their trust in certain cancer information websites (source) as well as their trust in the internet as a

149 medium of cancer information.

150 Consumers' trust in health information websites can be influenced by various factors. Two

151 systematic reviews (Kim 2016; Sbaffi \& Rowley 2017) assessed these factors, which can be

152 organized into three categories as follows. (1) Individual consumer characteristics: consumers

153 who are younger, are mostly highly educated, are female, have a higher level of agreeableness,

154 have a higher income, reported being in good health condition and have a higher level of health

155 literacy appear to be more trusting of health information websites. (2) Website-related factors:

156 websites that are complete, understandable, unbiased, modern, useful, and easy to navigate; have

157 a clear and professional layout; are easy to access; are run by medical universities or the federal

158 government; and contain high-quality information are more likely to be trusted. (3) Consumer-

159 to-website interaction-related factors: experience in using the internet and familiarity with the 
160 website are likely to influence consumer trust in the health information. Experienced users are

161 more confident in the internet and less concerned over the risks entailed in its use, thereby

162 increasing the likelihood of trusting health-related websites. Additionally, patients prefer health

163 information written by people experiencing similar health issues (Kim 2016; Sbaffi \& Rowley

164 2017).

165 In summary, it can be stated that cancer patients can only benefit from online cancer information

166 if they can trust the information or the internet as a medium of this information. To date, no

167 systematic review that analyzed cancer patients' trust in online health information has been

168 published. The primary goal of this systematic review is to identify the extent to which cancer

169 patients trust cancer-related online information, internet websites as a source of cancer-related

170 information or the internet as a medium of cancer-related information. As a secondary goal, the

171 review seeks to determine whether trust in cancer-related online information differs across

172 patients of different ages, genders, health statuses, education levels or cancer types.

\section{Methods}

174 A systematic literature review was conducted to explore cancer patients' trust in cancer-related 175 online information, internet websites as a source of cancer-related information or in the internet 176 as a medium of cancer information. The protocol for the systematic review was registered in the

177 international prospective register of reviews (PROSPERO) with the registration code

178 CRD42017070190 (File S1). Additionally, the reporting of this review followed the

179 recommendations of the PRISMA statement (Moher et al. 2009), an evidence-based minimum

180 set of items for reporting in systematic reviews and meta-analyses (Table S1). 


\section{Information sources and search strategy}

182 We performed an electronic literature search of the electronic databases Medline, CINAHL, Web

183 of Science, PsycINFO and PSYINDEX using prespecified search terms with no restriction on the

184 publication period. All searches were performed on the $4^{\text {th }}$ of January 2017 (last update, $4^{\text {th }}$ of

185 October 2018). Additionally, the reference lists of the included studies were manually searched

186 for potentially relevant studies.

187 To systematically identify search terms that could address the research questions, the PICO

188 criteria were adapted. PICO criteria can help facilitate the process of finding an answer to a

189 clinical question, by identifying appropriate keywords that can be used to conduct a literature

190 search (Richardson et al. 1995; van Loveren \& Aartman 2007). The focus was on the following

191 criteria: (P) population (cancer patients); and (O) outcome (trust/distrust/evaluation of

192 credibility). We included all studies independent of being an intervention study or the presence

193 or absence of a comparison group. Therefore, we did not specify the intervention (I) or

194 comparison (C) in our research question. Additional search terms were selected after an analysis

195 of the Medical Subject Headings (MeSH) and text words used in key articles, which were

196 identified in prior nonsystematic exploratory literature searches. The included search terms were

197 discussed by the authors and then arranged to create a search string. The search strings were used

198 in each database and accounted for synonyms, plurals, hyphenations and multiple word

199 combinations. All search results were exported into EndNote X7, and all duplicates were

200 removed. The search strategy for MEDLINE is provided in Table S2. The search strategy was

201 appropriately modified for each database to identify eligible studies. 


\section{Eligibility criteria}

203 All studies obtained from the initial search had to fulfill the inclusion criteria of the two selection

204 phases. During the first phase, the corresponding author screened the titles and abstracts of all

205 studies. Consistent with the broad research questions, studies of any type were included if the

206 study title or abstract stated that cancer patients or cancer survivors of any age and with any type

207 of cancer participated in the study and if one of the reported outcomes appeared to be

208 participants' trust, perceptions of credibility or distrust in online cancer-related information,

209 internet websites as a source of cancer-related information or in the internet as a medium of

210 cancer information.

211 During the second phase, two researchers independently assessed the full texts of the remaining

212 potentially relevant articles. The eligibility criteria used in the full text screening addressed two

213 aspects: study characteristics and report characteristics (Liberati et al. 2009). The inclusion

214 criteria for study characteristics were as follows: : (1) the full text was available; (2) any study

215 type was included if it included some form of quantitative data; (3) at least some of the

216 participants were cancer patients or cancer survivors; (4) the participants were 18 years or older;

217 (5) the measured constructs were trust, perceived credibility or distrust; and (6) the study

218 measured participants' trust in online cancer-related information, internet websites as a source of

219 cancer-related information or the internet as a medium of cancer-related information. The

220 reporting of the study had to meet one inclusion criterion: (1) the study was included in the

221 review if it was reported in English or German. Disagreements between the researchers regarding

222 the eligibility of studies were resolved via discussion. The reasons for exclusion and the number

223 of studies excluded for each reason can be found in Table S3. 


\section{Data extraction and quality assessment}

225 Data extraction was performed by the corresponding author (LL) and cross-checked by another 226 member (MLP) of the research group. The following data were extracted from the included

227 studies: (1) study characteristics, including the author name, year of publication, title of

228 publication, place of data collection, study design, and sample size; (2) characteristics of the

229 study participants, such as age, gender, cancer type, education status, health status; (3) outcome

230 characteristics, such as questionnaire or items used to measure trust; and (4) the measured

231 outcome of trust, perceived credibility or distrust (i.e., as the mean or distribution). Additionally,

232 six corresponding authors of the studies in question were contacted for further information (e.g.,

233 questionnaires, data sets); four of them responded. Most provided additional information

234 concerning their publications. Three authors provided additional descriptive information, and the

235 fourth author shared the complete data file of the study results.

236 The methodological quality assessment of the included papers was independently performed by

237 two researchers in the study group and based on the RTI item bank (Viswanathan et al. 2013).

238 The RTI item bank provided the researchers with a set of items to evaluate the conduct of

239 observational studies included in systematic reviews and to detect possible risks of biases of the

240 included studies (Viswanathan \& Berkman 2012; Viswanathan et al. 2013). Studies were not

241 excluded from the review or any subsequent analyses on the basis of the risk of bias. In

242 accordance with the developers' instructions, the instrument was adapted to fit the designs of the

243 included observational studies. Seven questions (questions 1, 2, 3, 6, 9, 11, 13) were used to

244 assess selection bias, detection bias, confounding, selective outcome reporting and overall bias in

245 the included studies. The reasons for not integrating the additional questions of the RTI item 
246 bank into the quality assessment can be found in Table S4. Disagreements between the two

247 reviewers regarding the assessed quality of the studies were resolved via discussion.

\section{Data analysis and description}

249 A narrative synthesis was undertaken to examine the included studies (Dixon-Woods et al.

250 2005). Furthermore, the characteristics and results of the included studies were summarized

251 descriptively.

252 No planned meta-analysis was conducted to answer the secondary study goal (does trust in

253 online cancer-related information, internet websites as a source of cancer-related information or

254 in the internet as a source medium of cancer information differ across patients with different

255 ages, genders, education levels, health status or cancer types) because only two of the included

256 studies reported between-group comparisons for these patient characteristics. However, to

257 illustrate the between-group comparisons of individual studies, we calculated the mean

258 differences (MDs) by subtracting the mean score of one group of participants (i.e., female

259 patients), which was expected to score higher, from the mean score of the second group of

260 participants (i.e., male patients). For clarity, all the mean trust scores reported in the included

261 studies were transformed into a 5-point scale (range, 1-5).

\section{Results}

\section{Study selection}

264 The search of the databases (Medline, CINHAL, Web of Science, PsychINFO and PSYINDEX)

265 resulted in 7314 citations (Fig. 1). All citations are available at Figshare

266 (https://doi.org/10.6084/m9.figshare.7701014.v1). After the removal of duplicate articles, 6132

267 titles and abstracts were scanned for eligibility. Of these, 54 studies fulfilled the eligibility

268 criteria of the first selection phase. Four additional studies were added after the reference lists of 
269 the 54 potentially relevant studies were manually searched. The full text of two articles could not

270 be retrieved despite contacting the authors. Of the remaining 51 articles, 7 (Crutzen et al. 2014;

271 Losken et al. 2005; Lussiez et al. 2017; Mayer et al. 2007; Pereira et al. 2000; Roach et al. 2009;

272 Shea-Budgell et al. 2014) met the eligibility criteria of the second phase and were therefore

273 included in the review.

274 Fig. 1. Flowchart of the literature search.

275 Study characteristics

276 The characteristics of all the articles are described in Table 1. All studies were published in

277 English in peer reviewed journals between 2000 and 2014. Six of the seven studies were

278 performed in North America (USA and Canada), and one (Crutzen et al. 2014) was conducted in

279 Europe (Netherlands). Four studies used on-site recruitment of participants visiting outpatient

280 facilities for treatment or checkups (Losken et al. 2005; Lussiez et al. 2017; Pereira et al. 2000;

281 Shea-Budgell et al. 2014). Two studies (Mayer et al. 2007; Roach et al. 2009) called patients at

282 their homes, and one study (Crutzen et al. 2014) recruited participants online. All seven studies

283 were cross-sectional. Five of the studies performed out to answer broad research questions, while

284 two studies (Lussiez et al. 2017; Roach et al. 2009) formulated hypotheses. Three of the studies

285 formulated the intention to describe the general internet use of patients with any type of cancer

286 (Losken et al. 2005; Pereira et al. 2000; Shea-Budgell et al. 2014). One study intended to provide

287 insights into user perceptions related to loyalty towards a specific Dutch cancer information

288 website (Crutzen et al. 2014). The website offered tailored, hospital-specific information on

289 oncological care and detailed information about health care professionals, and it was constantly

290 reviewed and updated by professionals in oncology care. Another study aimed to describe

291 differences between cancer survivors who do and do not seek cancer information off- or online 
292 (Mayer et al. 2007). The authors of the sixth and seventh study hypothesized that cancer patients

293 are more likely to search for cancer information (Lussiez et al. 2017; Roach et al. 2009), higher

294 income and education levels correlate with increased internet use for health information (Lussiez

295 et al. 2017) and cancer patients are more likely to have an increased knowledge of cancer-related

296 information sources than healthy individuals (Roach et al. 2009).

297 All but one study used one item scored on a 3- to 5-point scale to measure the participants' trust

298 in information found on the internet (Losken et al. 2005; Lussiez et al. 2017; Pereira et al. 2000)

299 or the internet as a medium of health information (Mayer et al. 2007; Roach et al. 2009; Shea-

300 Budgell et al. 2014). The seventh study used 3 items scored on a 7-point Likert scale to measure

301 patients' trust in one specific cancer information website (Crutzen et al. 2014). Convenience and

302 purposive sampling methods were applied in five studies, while two studies (Mayer et al. 2007;

303 Roach et al. 2009) applied stratified sampling with oversampling of minority groups. The sample

304 sizes of cancer patients in the included studies ranged from 63 to 719 (median, 157).

305 Table 1. Characteristics of the included cross-sectional studies.

306 Synthesis of the results

307 The study results were grouped into three themes based on the study goals: (1) characteristics of 308 the included study samples; (2) cancer patients' trust in cancer- or health-specific online 309 information, in internet websites as a source of cancer-related information or in the internet as a

310 medium of cancer information; and (3) between-group comparison of patient characteristics (age,

311 gender, education and cancer type). A full overview of the results is displayed in Table 2.

\section{Table 2. Outcomes of the included studies.}




\section{Sample characteristics of the included studies}

314 In the five studies that reported the participants' age, the mean age was 56 years (range, 47 to

315 58). In the five studies that reported the participants' education levels, the largest group in each

316 study was highly educated. Two studies did not report their participants' education levels

317 (Lussiez et al. 2017; Roach et al. 2009).

318 Three studies (Mayer et al. 2007; Roach et al. 2009; Shea-Budgell et al. 2014) included cancer

319 patients with various types of cancer, while three studies (Losken et al. 2005; Lussiez et al. 2017;

320 Pereira et al. 2000) focused on particular types. Two studies (Losken et al. 2005; Pereira et al.

321 2000) focused on breast cancer patients, while one (Lussiez et al. 2017) focused on lung or

322 esophageal cancer. One study did not report the cancer types of the included participants

323 (Crutzen et al. 2014). Six of the seven studies that reported the participants' gender included

324 more female than male participants (63\% females among the 1347 participants).

\section{Cancer patients' trust in online cancer information}

326 Approximately half of the 2041 cancer patients who participated in all of the included studies

327 combined appeared to trust online cancer information $(\overline{\mathrm{x}}=3.1, \mathrm{SD}=1.4)$. A total of 1054

328 patients reported having some or a lot of trust in cancer information obtained online, while 154

329 patients reported moderately trusting or being undecided about whether they should trust online

330 health information, and 833 patients reported having no or a little trust in cancer-related

331 information found on the internet or in the internet as a medium of cancer-related information.

332 Regarding the individual results of each study, two points are apparent. In all studies but one

333 (Roach et al. 2009), the majority of the participants reported having some or a lot of trust in

334 online cancer information. Additionally, 55\% of breast cancer patients in outpatient treatment

335 stated that they were undecided about whether to trust online information (Pereira et al. 2000). 
336 Three of the included studies indicated that the internet appears to be the second-most-trusted

337 medium of cancer information after health care professionals (Mayer et al. 2007; Roach et al.

338 2009; Shea-Budgell et al. 2014). Patients were more likely to trust online information than

339 information from newspapers, magazines, the radio, family or friends or the television.

340 Between-group comparisons of patient characteristics

341 Two of the seven studies reported between-group comparisons of characteristics that might

342 influence patients' trust in online health information. One study found that participants were

343 more likely to be very trustful of information found online if they had a higher education level

344 (Lussiez et al. 2017). The authors of the second study stated that no significant associations were

345 detected between cancer site and level of trust (Shea-Budgell et al. 2014). The conclusions of

346 both studies could not be verified or replicated because the necessary descriptive data were not

347 reported.

348 Furthermore, the corresponding author of one study (Crutzen et al. 2014) provided his entire data

349 set, which made it possible to calculate two additional results. The MD of the reported trust

350 between patients with high and low education levels was -0.58 ( $95 \%$ confidence interval (CI): -

$3511.64,0.48)$ with a medium effect size; between female and male patients, the MD was $0.13(95 \%$

352 CI: -0.45, 0.71), with a small effect size (Crutzen et al. 2014).

353 Additionally, two studies reported between-groups comparisons of patients' trust as related to

354 patient characteristics that were not part of the secondary research question. The MDs in the

355 reported trust between cancer patients and healthy control groups were -0.03 ( $95 \%$ CI: -0.33 ,

356 0.27) (Roach et al. 2009) and -0.07 (95\% CI: -0.21, 0.06) (Crutzen et al. 2014), with a small

357 effect. The MD between patients who had personally sought cancer information and those who

358 had not was 1.14 (95\% CI: 0.88, 1.40), with a large effect size (Mayer et al. 2007). 


\section{Quality assessment}

360 The detailed methodological quality ratings of the included studies are displayed in Table 3 . An

361 estimation of the selection bias is covered by questions one to three. The inclusion criteria did

362 not vary across individuals in three of the included studies (question 1). However, four studies

363 failed to report the inclusion criteria (Crutzen et al. 2014; Lussiez et al. 2017; Mayer et al. 2007;

364 Roach et al. 2009). None of the studies used different recruitment measures across individuals

365 (question 2). The selection of an appropriate comparison group was not relevant to the included

366 studies as none of them included a comparison group (question 3).

367 Question six gives an indication of the detection bias of the included studies. Three studies

368 (Crutzen et al. 2014; Mayer et al. 2007; Roach et al. 2009) used valid and reliable instruments,

369 while the remaining four studies used self-developed questionnaires that were not

370 psychometrically validated. Question nine asks whether the researchers were selective in their

371 outcome reporting. None of the seven studies failed to report the results of any of the important

372 primary outcomes. Confounding was accounted for in all studies by believably taking study

373 limitations into consideration (question 11). Question thirteen asks whether important

374 confounding variables were taken into account in the design and/ or the analysis. Five of the

375 studies did take important confounding variables into account. One study reported the descriptive

376 results of possible confounders such as age or education, but did not investigate whether any of

377 the confounders had an influence on the measured outcome (Losken et al. 2005). Another study

378 did not state whether the types of information the patients sought varies by any socioeconomic

379 factors (Shea-Budgell et al. 2014).

380 Table 3. Risk of bias appraisal using the RTI item bank. 
381 Discussion

382 This review includes seven studies that describe cancer patients' trust in cancer-related online

383 information. Overall, approximately half of the cancer patients in the included studies reported

384 that they trusted cancer-related online information, internet websites as a source of cancer-related

385 information or the internet as a medium of cancer-related information.

386 There appears to be differences in the results of the seven included studies. The lowest trust

387 scores were reported in the three studies with the largest samples of cancer patients with various

388 types of cancer (Mayer et al. 2007; Roach et al. 2009; Shea-Budgell et al. 2014). In these studies,

389 the participants were asked to appraise their trust in the internet as a medium of cancer-related

390 information. In three of the other four studies (Losken et al. 2005; Lussiez et al. 2017; Pereira et

391 al. 2000), the participants were asked how much they trusted the cancer- or health-specific

392 information they found online. The seventh study measured patients' trust in one specific cancer

393 information website (Crutzen et al. 2014). Possible explanations for the differences in trust

394 reported by the groups of participants in these studies might be the formulation of the items that

395 measured patients' trust or the gender of the study participants. When patients are asked to report

396 how much they trust the information they find online, they might be more likely to interpret the

397 question as a rating of their information literacy (Shenton 2009) or eHealth literacy (Norman \&

398 Skinner 2006), which are defined as the skills needed to find, retrieve and analyze information in

399 general (information literacy) or health information online (eHealth literacy) and use it

400 appropriately. The potential bias that occurs when patients rate their own information literacy or

401 eHealth literacy is that people are likely to overestimate their own abilities (Merritt et al. 2005;

402 Mohmood 2016 ; van der Vaart et al. 2011). Furthermore, two of the studies with higher reported 403 trust scores (Losken et al. 2005; Pereira et al. 2000) mainly focused on breast cancer patients. 
404 These studies reported mean trust levels of 4.3 and 3.5, which is in line with prior research that

405 stated that female consumers are more likely to trust online information (Kim 2016; Sbaffi \&

406 Rowley 2017). Nevertheless, a between-group comparison within the studies showed no

407 difference between female and male patients.

408 The internet appears to be the second-most-trusted cancer information medium behind health

409 care professionals (Mayer et al. 2007; Roach et al. 2009; Shea-Budgell et al. 2014). Patients are

410 more likely to trust online information than information from newspapers, magazines, the radio,

411 family or friends or the television. A possible explanation might be that the internet offers

412 information that has greater relevance to the consumer and therefore is considered more

413 trustworthy (Song \& Zahedi 2007). Magazines, radio and television present information that

414 might target cancer patients or patients with a certain cancer type, whereas the internet allows

415 cancer patients to search for information that is relevant to their individual situation or question.

416 The number of breast cancer patients in one of the included studies (Pereira et al. 2000) that

417 reported that they were undecided regarding whether they should trust the medical information

418 they found online was higher than expected. A possible explanation might be the varying quality

419 of online information, which makes it difficult for cancer patients to make well-informed

420 medical decisions (Al-Bahrani \& Plusa 2004; Borgmann et al. 2016; Bruce et al. 2015; Hargrave

421 et al. 2006; Liebl et al. 2015; Nghiem et al. 2016; Ni Riordain \& McCreary 2009; Wasserman et

422 al. 2014). Physicians and oncologists should adopt an intermediary role when they discuss

423 internet information with their patients. They should be able recommend reliable online

424 information sources to their patients and help them understand and discuss the information found

425 there (Halwas et al. 2017). Patients who search for information should not be viewed as a threat 
426 (Helft et al. 2003) but as an opportunity to increase communication and shared decision-making

427 ability (Kehl et al. 2015).

428 It was not possible to answer the secondary research question: Does trust in online health

429 information differ between cancer patients with different ages, genders, health status or

430 education levels? Most of the included studies did not examine how patients' characteristics

431 influence the amount of reported trust in online health information as measuring trust was not

432 their main research goal. The results of the included studies that did examine within-group

433 differences did not always confirm the results of recent systematic reviews that identified

434 consumer characteristics that might influence the reported trust in health information websites

435 (Kim 2016; Sbaffi \& Rowley 2017): In one study, as expected, female patients reported higher

436 levels of trust (Crutzen et al. 2014). The effect size for the MD between females and males was

437 quite small. The results of the comparisons between patients with higher and lower education

438 levels within the studies were mixed. One study (Lussiez et al. 2017) reported the expected

439 difference, while the other study (Crutzen et al. 2014) stated that patients with lower education

440 levels were more likely to trust online information. There appears to be no explanation for the

441 higher mean trust scores of the low-education patient groups compared with the high-education

442 patient groups. However, the study sample of cancer patients with low education levels only

443 included five individuals (Crutzen et al. 2014) and therefore may not represent the entire

444 population of cancer patients with low education levels. A within-study comparison indicated

445 that cancer type appeared to have no influence on the reported trust in online cancer information

446 (Shea-Budgell et al. 2014). The absence of a difference among different cancer types did not

447 contradict any study findings. Cancer type was added to the list of possible confounding

448 variables because a difference in reported trust was expected due to differences in attitudes 
449 towards eHealth among patients with different types of cancer (Jansen et al. 2015). The MD in

450 reported trust between patients who had personally sought cancer information and those who had

451 not had a large effect size. This effect may be explained by differences in research findings.

452 Patients who are searching for cancer information are more likely to have completed a higher

453 level of education (Ramanadhan \& Viswanath 2006), which is again associated with a higher

454 tendency to trust online information (Kim 2016; Sbaffi \& Rowley 2017). Additionally,

455 experienced users are more confident in the internet and less concerned over the risks entailed in

456 its use, both of which have a positive influence on trust (Kim 2016).

457 In terms of the methodological quality of the included studies, it should be noted that the

458 assumptions of this review are exclusively based on the results of cross-sectional studies, which

459 are likely to have different biases (Viswanathan \& Berkman 2012). Overall, the assessment of

460 the included studies with the RTI item bank indicated that estimations of selective outcome

461 reporting, confounding and overall assessment gave a positive impression of the methodological

462 quality of the included studies. However, four studies failed to report whether the inclusion

463 criteria varied across participants. Due to the lack of information on inclusion criteria, a selection

464 bias cannot be ruled out which may limit the generalizability of the study results (Hernán et al.

465 2004). However, not reporting the inclusion criteria only allow conclusions to be drawn about

466 the reporting quality of the included studies, but not about the quality of the studies (Margulis et

467 al. 2014). Additionally, only three of the studies used valid and reliable instruments, which is an

468 indicator for detection bias (Viswanathan et al. 2013). Additional research needs to be conducted

469 using a validated instrument to measure patients' trust in cancer-related information websites.

470 Six of the studies only used one item to measure the primary outcome of trust, creating a possible

471 source of bias. Latent variables are usually complex and not easily measured. The use of multiple 
472 items helps to average out errors that are inherent in single items and therefore have higher

473 reliability and criterion validity than a single item (Sarstedt \& Wilczynski 2009). Single items

474 have practical advantages, such as parsimony and ease of administration (Bergkvist \& Rossiter

475 2009), and they usually promote higher response rates (Bergkvist \& Rossiter 2007). However,

476 they only perform as well as multi-item scales under very specific conditions (Diamantopoulos et

477 al. 2012). Under these conditions, the construct should be unidimensional and unambiguous to

478 the respondent (Wanous et al. 1997). Examples of these types of constructs are job satisfaction

479 (Wanous et al. 1997) and attitude towards advertisement and brand in marketing (Bergkvist \&

480 Rossiter 2007; Bergkvist \& Rossiter 2009). Because assessing trust in information always will

481 contain a certain degree of heuristics (Lucassen et al. 2013), it appears as if one item might

482 provide a sufficient indication of whether cancer patient trust online information or the internet

483 as an information source. Nevertheless, there appears to be a need for validated questionnaires

484 that measure consumers' trust in online health information.

485 Strengths and limitations

486 This systematic review has some limitations. Its main limitation is the lack of knowledge of the

487 webpages that formed the basis of the study participants' trust assessments. As stated in the

488 introduction, the quality of the cancer-related information that can be accessed on the internet is

489 highly variable (Al-Bahrani \& Plusa 2004; Borgmann et al. 2016; Bruce et al. 2015; Hargrave et

490 al. 2006; Liebl et al. 2015; Nghiem et al. 2016; Ni Riordain \& McCreary 2009; Wasserman et al.

491 2014). When participants had a negative prior experience with cancer websites, they were more

492 likely to report low levels of trust (Kim 2016). Furthermore, only studies written in German and

493 English were included in the study. Therefore, studies in other languages that examine cancer

494 patients' trust in cancer-related online information might be missing from this systematic review. 
495 Another limitation could be that six of the seven included studies were conducted in North

496 America, and only one was conducted in Europe, although there appears to be only small

497 differences in the reported internet utilization of these populations (Poushter 2016). We can

498 therefore only draw conclusions about North American cancer patients. No gray literature was

499 included in the review. Therefore, we missed the opportunity to minimize the effects of

500 publication bias and to represent the entire evidence base as studies that show statistically

501 significant, positive results have a better chance of being published (Blackhall \& Ker 2007;

502 Hopewell et al. 2007).

503 In addition to the limitations, this review also has distinct strengths. First, because the authors

504 aimed to provide a broad picture of cancer patients' trust in online health information, the study

505 used a systematic search strategy of five electronic databases, which resulted in a heterogeneous

506 sample of studies and did not exclude studies due to their design or quality. Additionally, the

507 search strategy used appeared to be successful as only four additional studies could be identified

508 through manual searches of the reference lists of studies that fulfilled the eligibility criteria of the

509 first selection phase, and none of these four studies was included in the review. A further

510 strength is the methodological quality assessment of the included papers, which was

511 independently performed by two researchers according to the reporting guidelines of the

512 PRISMA statement (Moher et al. 2009). Finally, this systematic review was registered in

513 PROSPERO to achieve transparency.

\section{Conclusions}

515 This systematic review included seven cross-sectional studies out of 7314 citations obtained

516 from a search. The results of the included studies indicate that approximately half of cancer

517 patients appear to trust information found on the internet, internet websites as a source of cancer- 
518 related information or trust the internet itself as a medium of cancer information. However, the

519 small number of included studies, high heterogeneity of participants, methods and outcomes, and

520 the diverse quality of the included studies call for further systematic research.

521 Further research on cancer patients needs to be conducted using a validated instrument to

522 measure patients' perceived trust and the credibility of health information websites, especially

523 for groups of patients such as older adults and those with a low socioeconomic status, who

524 appear to have lower online information searching skills and tend to be less likely to trust cancer

525 information found online.

526 Furthermore, it is important to understand that cancer patients' decision making is influenced by

527 online information and that even if the physician remains the most trusted medium of advice,

528 patients do and will increasingly use cancer-related websites to search information concerning

529 their disease and its treatment. Therefore, physicians, nurses and other health care providers

530 should provide more support and advice to patients seeking health information. Additionally,

531 patients should be encouraged to ask their doctors questions and to discuss the results of their

532 online information searches with them to ensure that false information is not included.

\section{Acknowledgments}

534 The authors of this systematic review wish to acknowledge the authors of the included studies for

535 their cooperation.

\section{References}

Al-Bahrani A, and Plusa S. 2004. The quality of patient-orientated internet information on colorectal cancer. Colorectal disease : the official journal of the Association of Coloproctology of Great Britain and Ireland 6:323-326. DOI: 10.1111/j.1463-1318.2004.00604.x.

Bergkvist L, and Rossiter JR. 2007. The predictive validity of multiple-item versus single-item measures of the same constructs. Journal of Marketing Research 44:175-184.

Bergkvist L, and Rossiter JR. 2009. Tailor-made single-item measures of doubly concrete constructs. International Journal of Advertising 28:607-621. DOI: 10.2501/s0265048709200783. 
544

545

546

547

548

549

550

551

552

553

554

555

556

557

558

559

560

561

562

563

564

565

566

567

568

569

570

571

572

573

574

575

576

577

578

579

580

581

582

583

584

585

586

587

588

589

590

Blackhall K, and Ker K. 2007. Finding studies for inclusion in systematic reviews of interventions for injury prevention - the importance of grey and unpublished literature. Injury Prevention 13:359. DOI: 10.1136/ip.2007.017020.

Borgmann H, Mager R, Salem J, Brundl J, Kunath F, Thomas C, Haferkamp A, and Tsaur I. 2016. Robotic prostatectomy on the web: A cross-sectional qualitative assessment. Clinical genitourinary cancer 14:e355-362. DOI: 10.1016/j.clgc.2015.12.020.

Broom A. 2005. Virtually he@lthy: the impact of internet use on disease experience and the doctorpatient relationship. Qualitative health research 15:325-345. DOI: 10.1177/1049732304272916.

Bruce JG, Tucholka JL, Steffens NM, and Neuman HB. 2015. Quality of online information to support patient decision-making in breast cancer surgery. Journal of surgical oncology 112:575-580. DOI: 10.1002/jso.24046.

Castleton K, Fong T, Wang-Gillam A, Waqar MA, Jeffe DB, Kehlenbrink L, Gao F, and Govindan R. 2011. A survey of Internet utilization among patients with cancer. Supportive care in cancer: official journal of the Multinational Association of Supportive Care in Cancer 19:1183-1190. DOI: 10.1007/s00520-010-0935-5.

Charnock D, Shepperd S, Needham G, and Gann R. 1999. DISCERN: an instrument for judging the quality of written consumer health information on treatment choices. Journal of epidemiology and community health 53:105-111.

Chen X, and Siu LL. 2001. Impact of the media and the internet on oncology: survey of cancer patients and oncologists in Canada. J Clin Oncol 19:4291-4297. DOI: 10.1200/jco.2001.19.23.4291.

Chiu YC. 2011. Probing, impelling, but not offending doctors: the role of the internet as an information source for patients' interactions with doctors. Qualitative health research 21:1658-1666. DOI: $10.1177 / 1049732311417455$.

Chou WY, Liu B, Post S, and Hesse B. 2011. Health-related internet use among cancer survivors: data from the Health Information National Trends Survey, 2003-2008. J Cancer Surviv 5:263-270. DOI: 10.1007/s11764-011-0179-5.

Crutzen R, Beekers N, van Eenbergen M, Becker M, Jongen L, and van Osch L. 2014. E-loyalty towards a cancer information website: applying a theoretical framework. Psychooncology 23:685-691. DOI: 10.1002/pon.3471.

Davey HM, Butow PN, and Armstrong BK. 2003. Cancer patients' preferences for written prognostic information provided outside the clinical context. British journal of cancer 89:1450-1456. DOI: 10.1038/sj.bjc.6601287.

Davies NJ, Kinman G, Thomas RJ, and Bailey T. 2008. Information satisfaction in breast and prostate cancer patients: implications for quality of life. Psycho-Oncology 17:1048-1052. DOI: 10.1002/pon.1305.

Diamantopoulos A, Sarstedt M, Fuchs C, Wilczynski P, and Kaiser S. 2012. Guidelines for choosing between multi-item and single-item scales for construct measurement: a predictive validity perspective. Journal of the Academy of Marketing Science 40:434-449. DOI: 10.1007/s11747011-0300-3.

Dixon-Woods M, Agarwal S, Jones D, Young B, and Sutton A. 2005. Synthesising qualitative and quantitative evidence: a review of possible methods. Journal of health services research \& policy 10:45-53. DOI: 10.1177/135581960501000110.

Dutton WH, and Shepherd A. 2006. Trust in the Internet as an experience technology. Information, Communication \& Society 9:433-451. DOI: 10.1080/13691180600858606.

Eysenbach G, and Köhler C. 2002. How do consumers search for and appraise health information on the world wide web? Qualitative study using focus groups, usability tests, and indepth interviews. BMJ (Clinical research ed) 324:573.577.

Peer) reviewing PDF | (2019:02:34973:1:1:NEW 15 Jul 2019) 
591

592

593

594

595

596

597

598

599

600

601

602

603

604

605

606

607

608

609

610

611

612

613

614

615

616

617

618

619

620

621

622

623

624

625

626

627

628

629

630

631

632

633

634

635

636

637
Finney Rutten LJ, Agunwamba AA, Wilson P, Chawla N, Vieux S, Blanch-Hartigan D, Arora NK, Blake K, and Hesse BW. 2016. Cancer-related information seeking among cancer survivors: trends over a decade (2003-2013). Journal of Cancer Education 31:348-357. DOI: 10.1007/s13187-015-0802-7.

Fisher J, Burstein F, Lynch K, and Lazarenko K. 2008. "Usability + usefulness = trust": an exploratory study of Australian health web sites. Internet Research 18:477-498. DOI: 10.1108/10662240810912747.

Fogg BJ, and Tseng H. 1999. The elements of computer credibility. Proceedings of the SIGCHI conference on Human Factors in Computing Systems. Pittsburgh, Pennsylvania, USA: ACM. p 80-87.

Fox S. 2006. Online Health Search 2006. Washington DC: Pew Internet \& American Life Project.

Halwas N, Griebel L, and Huebner J. 2017. eHealth literacy, Internet and eHealth service usage: a survey among cancer patients and their relatives. Journal of cancer research and clinical oncology 143:2291-2299. DOI: 10.1007/s00432-017-2475-6.

Hargrave DR, Hargrave UA, and Bouffet E. 2006. Quality of health information on the Internet in pediatric neuro-oncology. Neuro-oncology 8:175-182. DOI: 10.1215/15228517-2005-008.

Harrison JD, Young JM, Price MA, Butow PN, and Solomon MJ. 2009. What are the unmet supportive care needs of people with cancer? A systematic review. Supportive care in cancer : official journal of the Multinational Association of Supportive Care in Cancer 17:1117-1128. DOI: 10.1007/s00520-009-0615-5.

Helft PR, Hlubocky F, and Daugherty CK. 2003. American oncologists' views of internet use by cancer patients: a mail survey of American Society of Clinical Oncology members. Journal of clinical oncology : official journal of the American Society of Clinical Oncology 21:942-947. DOI: 10.1200/JCO.2003.08.007.

Hernán MA, Hernández-Díaz S, and Robins JM. 2004. A Structural Approach to Selection Bias. Epidemiology 15:615-625. DOI: 10.1097/01.ede.0000135174.63482.43.

Hopewell S, McDonald S, Clarke M, and Egger M. 2007. Grey literature in meta-analyses of randomized trials of health care interventions. The Cochrane database of systematic reviews. DOI: 10.1002/14651858.MR000010.pub3.

Jansen F, van Uden-Kraan CF, van Zwieten V, Witte BI, and Verdonck-de Leeuw IM. 2015. Cancer survivors' perceived need for supportive care and their attitude towards self-management and eHealth. Supportive care in cancer : official journal of the Multinational Association of Supportive Care in Cancer 23:1679-1688. DOI: 10.1007/s00520-014-2514-7.

Jenkins V, Fallowfield L, and Saul J. 2001. Information needs of patients with cancer: results from a large study in UK cancer centres. British journal of cancer 84:48 -51. DOI: 10.1054/.

Kehl KL, Landrum MB, Arora NK, Ganz PA, van Ryn M, Mack JW, and Keating NL. 2015. Association of actual and preferred decision roles with patient-reported quality of care: shared decision making in cancer care. JAMA oncology 1:50-58. DOI: 10.1001/jamaoncol.2014.112.

Kelton K, Fleischmann KR, and Wallace WA. 2008. Trust in digital information. Journal of the American Society for Information Science and Technology 59:363-374. DOI: 10.1002/asi.20722.

Kim Y. 2016. Trust in health information websites: a systematic literature review on the antecedents of trust. Health Informatics Journal 22:355-369. DOI: 10.1177/1460458214559432.

Lemire M, Pare G, Sicotte C, and Harvey C. 2008. Determinants of Internet use as a preferred source of information on personal health. International journal of medical informatics 77:723-734. DOI: 10.1016/j.ijmedinf.2008.03.002.

Liberati A, Altman DG, Tetzlaff J, Mulrow C, Gotzsche PC, loannidis JP, Clarke M, Devereaux PJ, Kleijnen J, and Moher D. 2009. The PRISMA statement for reporting systematic reviews and meta-analyses of studies that evaluate healthcare interventions: explanation and elaboration. BMJ (Clinical research ed) 339:b2700. DOI: 10.1136/bmj.b2700.

Peer) reviewing PDF | (2019:02:34973:1:1:NEW 15 Jul 2019) 
638

639

640

641

642

643

644

645

646

647

648

649

650

651

652

653

654

655

656

657

658

659

660

661

662

663

664

665

666

667

668

669

670

671

672

673

674

675

676

677

678

679

680

681

682

683

684
Liebl P, Seilacher E, Koester MJ, Stellamanns J, Zell J, and Hubner J. 2015. What cancer patients find in the internet: the visibility of evidence-based patient information - analysis of information on German websites. Oncology research and treatment 38:212-218. DOI: 10.1159/000381739.

Losken A, Burke R, Elliott F, and Carlson GW. 2005. Infonomics and breast reconstruction - are patients using the internet? Annals of Plastic Surgery 54:247-250. DOI: 10.1097/01.sap.0000153159.53918.d4.

Lucassen T, Muilwijk R, Noordzij ML, and Schraagen JM. 2013. Topic familiarity and information skills in online credibility evaluation. Journal of the American Society for Information Science and Technology 64:254-264. DOI: 10.1002/asi.22743.

Lucassen T, and Schraagen JM. 2011. Factual accuracy and trust in information: The role of expertise. Journal of the American Society for Information Science and Technology 62:1232-1242. DOI: 10.1002/asi.21545.

Lucassen T, and Schraagen JM. 2012. Propensity to trust and the influence of source and medium cues in credibility evaluation. Journal of Information Science 38:566-577. DOI: 10.1177/0165551512459921.

Lussiez AD, Burdick S, Kodali S, Rubio G, Mack JA, Lin J, Chang AC, and Reddy RM. 2017. Internet usage trends in thoracic surgery patients and their caregivers. Journal of Cancer Education. DOI: 10.1007/s13187-015-0934-9.

Maddock C, Lewis I, Ahmad K, and Sullivan R. 2011. Online information needs of cancer patients and their organizations. Ecancermedicalscience 5:235. DOI: 10.3332/ecancer.2011.235.

Margulis AV, Pladevall M, Riera-Guardia N, Varas-Lorenzo C, Hazell L, Berkman ND, Viswanathan M, and Perez-Gutthann S. 2014. Quality assessment of observational studies in a drug-safety systematic review, comparison of two tools: the Newcastle-Ottawa Scale and the RTI item bank. Clin Epidemiol 6:359-368. DOI: 10.2147/CLEP.S66677.

Mattsson S, Olsson EMG, Johansson B, and Carlsson M. 2017. Health-related internet use in people with cancer: results from a cross-sectional study in two outpatient clinics in sweden. Journal of medical Internet research 19:e163. DOI: 10.2196/jmir.6830.

Mayer DK, Terrin NC, Kreps GL, Menon U, McCance K, Parsons SK, and Mooney KH. 2007. Cancer survivors information seeking behaviors: a comparison of survivors who do and do not seek information about cancer. Patient education and counseling 65:342-350. DOI: 10.1016/j.pec.2006.08.015.

Mayer R, Davis J, and Schoorman D. 1995. An Integrative Model of Organizational Trust. The Academy of Management Review 20:709-734. DOI: 10.2307/258792

Merritt K, Smith K, and Di Renzo J. 2005. An invesitgation of self reported computer literacy: is it reliable? Issues in Information Systems 6:289- 296.

Metzger MJ. 2007. Making sense of credibility on the Web: Models for evaluating online information and recommendations for future research. Journal of the American Society for Information Science and Technology 58:2078-2091. DOI: 10.1002/asi.20672.

Moher D, Liberati A, Tetzlaff J, and Altman DG. 2009. Preferred reporting items for systematic reviews and meta-analyses: the PRISMA statement. PLoS medicine 6:e1000097. DOI: 10.1371/journal.pmed.1000097.

Mohmood K. 2016 Do people overestimate their information literacy skills? A systematic review of empirical evidence on the Dunning-Kruger effect. Communications in Information Literacy 10:198-213.

Newnham GM, Burns WI, Snyder RD, Dowling AJ, Ranieri NF, Gray EL, and McLachlan SA. 2006. Information from the Internet: attitudes of Australian oncology patients. Journal of internal medicine 36:718-723. DOI: 10.1111/j.1445-5994.2006.01212.x.

Peer] reviewing PDF | (2019:02:34973:1:1:NEW 15 Jul 2019) 
685

686

687

688

689

690

691

692

693

694

695

696

697

698

699

700

701

702

703

704

705

706

707

708

709

710

711

712

713

714

715

716

717

718

719

720

721

722

723

724

725

726

727

728

729

730

731

Nghiem AZ, Mahmoud $\mathrm{Y}$, and Som R. 2016. Evaluating the quality of internet information for breast cancer. Breast 25:34-37. DOI: 10.1016/j.breast.2015.10.001.

Ni Riordain R, and McCreary C. 2009. Head and neck cancer information on the internet: type, accuracy and content. Oral oncology 45:675-677. DOI: 10.1016/j.oraloncology.2008.10.006.

Norman CD, and Skinner HA. 2006. eHealth literacy: essential skills for consumer health in a networked world. Journal of medical Internet research 8:e9. DOI: 10.2196/jmir.8.2.e9.

Pereira JL, Koski S, Hanson J, Bruera ED, and Mackey JR. 2000. Internet usage among women with breast cancer: an exploratory study. Clinical Breast Cancer 1:148-153. DOI: 10.3816/CBC.2000.n.013.

Poushter J. 2016. Smartphone Ownership and Internet Usage Continues to Climb in Emerging Economies.: Pew Research Center.

Ramanadhan S, and Viswanath K. 2006. Health and the information nonseeker: a profile. Health communication 20:131-139. DOI: 10.1207/s15327027hc2002_4.

Richardson WS, Wilson MC, Nishikawa J, and Hayward RS. 1995. The well-built clinical question: a key to evidence-based decisions. ACP J Club 123:A12-13.

Roach AR, Lykins ELB, Gochett CG, Brechting EH, Graue LO, Andrykowski MA, Roach AR, Lykins ELB, Gochett CG, Brechting EH, Graue LO, and Andrykowski MA. 2009. Differences in cancer information-seeking behavior, preferences, and awareness between cancer survivors and healthy controls: a national, population-based survey. Journal of cancer education : the official journal of the American Association for Cancer Education 24:73-79. DOI: 10.1080/08858190802664784.

Sarstedt M, and Wilczynski P. 2009. More for less? A comparison of single-item and multi-item measures. Die Betriebswirtschaft 69:211-228.

Sbaffi L, and Rowley J. 2017. Trust and Credibility in Web-Based Health Information: A Review and Agenda for Future Research. Journal of Medical Internet Research 19:e218. DOI: 10.2196/jmir.7579.

Shahrokni A, Mahmoudzadeh S, and Lu BT. 2014. In whom do cancer survivors trust online and offline? Asian Pacific Journal of Cancer Prevention 15:6171-6176. DOI: 10.7314/apjcp.2014.15.15.6171.

Shea-Budgell MA, Kostaras X, Myhill KP, and Hagen NA. 2014. Information needs and sources of information for patients during cancer follow-up. Current Oncology 21:165-173. DOI: 10.3747/co.21.1932.

Shenton AK. 2009. Information literacy and scholarly investigation: a British perspective. IFLA Journal 35:226-231. DOI: 10.1177/0340035209346219.

Sondergaard EG, Grone BH, Wulff CN, Larsen PV, and Sondergaard J. 2013. A survey of cancer patients' unmet information and coordination needs in handovers-a cross-sectional study. BMC research notes 6:378. DOI: 10.1186/1756-0500-6-378.

Song J, and Zahedi FM. 2007. Trust in health infomediaries. Decision Support Systems 43:390-407. DOI: 10.1016/j.dss.2006.11.011.

Tariman JD, Doorenbos A, Schepp KG, Singhal S, and Berry DL. 2014. Information needs priorities in patients diagnosed with cancer: a systematic review. Journal of the advanced practitioner in oncology 2014:115-122.

van de Poll-Franse LV, and van Eenbergen MC. 2008. Internet use by cancer survivors: current use and future wishes. Supportive care in cancer : official journal of the Multinational Association of Supportive Care in Cancer 16:1189-1195. DOI: 10.1007/s00520-008-0419-z.

van der Vaart R, van Deursen AJ, Drossaert CH, Taal E, van Dijk JA, and van de Laar MA. 2011. Does the eHealth Literacy Scale (eHEALS) measure what it intends to measure? Validation of a Dutch version of the eHEALS in two adult populations. Journal of medical Internet research 13:e86. DOI: 10.2196/jmir.1840.

Peer) reviewing PDF | (2019:02:34973:1:1:NEW 15 Jul 2019) 
732 van Loveren C, and Aartman IH. 2007. [The PICO (Patient-Intervention-Comparison-Outcome) question]. Ned Tijdschr Tandheelkd 114:172-178.

Viswanathan M, and Berkman ND. 2012. Development of the RTI item bank on risk of bias and precision of observational studies. Journal of clinical epidemiology 65:163-178. DOI:

736

737 10.1016/j.jclinepi.2011.05.008.

Viswanathan M, Berkman ND, Dryden DM, and Hartling L. 2013. AHRQ Methods for Effective Health Care. Assessing Risk of Bias and Confounding in Observational Studies of Interventions or Exposures: Further Development of the RTI Item Bank. Rockville (MD): Agency for Healthcare Research and Quality (US).

742

743

744

Wanous JP, Reichers AE, and Hudy MJ. 1997. Overall job satisfaction: how good are single-item measures? The Journal of applied psychology 82:247-252.

Wasserman M, Baxter NN, Rosen B, Burnstein M, and Halverson AL. 2014. Systematic review of internet patient information on colorectal cancer surgery. Diseases of the colon and rectum 57:64-69. DOI: 10.1097/DCR.0000000000000011.

Ziebland S, Chapple A, Dumelow C, Evans J, Prinjha S, and Rozmovits L. 2004. How the internet affects patients' experience of cancer: a qualitative study. BMJ (Clinical research ed) 328:564. DOI: 10.1136/bmj.328.7439.564. 
Figure 1 (on next page)

Flowchart of the literature search. 
Records identified through database searching $(\mathrm{n}=7314)$

Records after removing duplicates

$$
(n=6132)
$$

Records excluded

$$
(n=6078)
$$

Articles were added after manually searching the reference lists $(n=4)$ $(\mathrm{n}=6132)$
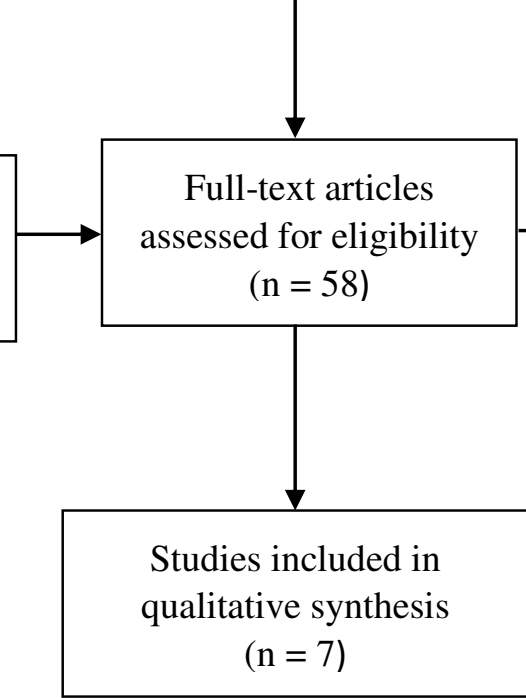

Peer) reviewing PDF | (2019:02:34973:1:1:NEW 15 Jul 2019)
Full-text articles excluded due to (no quantitative data, participants without cancer diagnosis, participants were 18 or older, measured construct was trust)

$$
(\mathrm{n}=51)
$$




\section{Table 1 (on next page)}

Study characteristics of the included cross sectional studies. 
Table 1:

2 Study characteristics of the included cross sectional studies.

\begin{tabular}{|c|c|c|c|c|c|c|c|}
\hline Study & Title & Year & Country & $\begin{array}{l}\text { Study } \\
\text { design }\end{array}$ & $\begin{array}{l}\text { Recruitment } \\
\text { strategy }\end{array}$ & Instruments to measure trust & Sampling method \\
\hline $\begin{array}{l}\text { (Crutze } \\
\text { n et al. } \\
2014)\end{array}$ & $\begin{array}{l}\text { E-loyalty towards } \\
\text { a cancer } \\
\text { information } \\
\text { website: applying } \\
\text { a theoretical } \\
\text { framework }\end{array}$ & 2014 & NL & $\mathrm{CS}$ & $\begin{array}{l}\text { Online } \\
\text { invitations to } \\
\text { visit the website } \\
\text { \& asking } \\
\text { visitors of the } \\
\text { website to } \\
\text { evaluate it }\end{array}$ & $\begin{array}{l}\text { Three items scored on a 7-point } \\
\text { Likert items ('strongly disagree' to } \\
\text { 'strongly agree') to measure trust in } \\
\text { one specific website }\end{array}$ & $\begin{array}{l}\text { Nonprobability } \\
\text { sampling: } \\
\text { convenience } \\
\text { sampling \& } \\
\text { purposive sampling }\end{array}$ \\
\hline $\begin{array}{l}\text { (Loske } \\
\text { n et al. } \\
2005)\end{array}$ & $\begin{array}{l}\text { Infonomics and } \\
\text { breast } \\
\text { reconstruction - } \\
\text { Are patients using } \\
\text { the internet? }\end{array}$ & 2005 & USA & $\mathrm{CS}$ & $\begin{array}{l}\text { On-site } \\
\text { recruitment } \\
\text { (first } \\
\text { postoperative } \\
\text { visit) }\end{array}$ & $\begin{array}{l}\text { One item scored on a 3-point item } \\
\text { format ('disagree' to 'agree'): "Did } \\
\text { you trust the information" found in } \\
\text { the internet }\end{array}$ & $\begin{array}{l}\text { Nonprobability } \\
\text { sampling: } \\
\text { purposive sampling }\end{array}$ \\
\hline $\begin{array}{l}\text { (Lussie } \\
\text { z et al. } \\
2015)\end{array}$ & $\begin{array}{l}\text { Internet usage } \\
\text { trends in thoracic } \\
\text { surgery patients } \\
\text { and their } \\
\text { caregivers }\end{array}$ & 2015 & USA & CS & $\begin{array}{l}\text { On-site } \\
\text { recruitment } \\
\text { (outpatient } \\
\text { clinic visit) }\end{array}$ & $\begin{array}{l}\text { One item scored on a 3-point item } \\
\text { format ('not trustful' to 'very } \\
\text { trustful') to measure the "level of } \\
\text { trust subjects placed in the } \\
\text { information they found" online }\end{array}$ & $\begin{array}{l}\text { Nonprobability } \\
\text { sampling: } \\
\text { purposive sampling }\end{array}$ \\
\hline $\begin{array}{l}\text { (Mayer } \\
\text { et al. } \\
2007)\end{array}$ & $\begin{array}{l}\text { Cancer survivors } \\
\text { information } \\
\text { seeking } \\
\text { behaviors: }\end{array}$ & 2007 & USA & $\mathrm{CS}$ & $\begin{array}{l}\text { Called via } \\
\text { telephone }\end{array}$ & $\begin{array}{l}\text { One item scored on a 4-point item } \\
\text { format ('not at all' to 'a lot') to } \\
\text { measure "how much they trusted } \\
\text { different sources of information" } \\
\text { (i.e., internet) }\end{array}$ & $\begin{array}{l}\text { Stratified sampling } \\
\text { with oversampling } \\
\text { of minority groups }\end{array}$ \\
\hline $\begin{array}{l}\text { (Pereira } \\
\text { et al. } \\
2000)\end{array}$ & $\begin{array}{l}\text { Internet usage } \\
\text { among women } \\
\text { with breast } \\
\text { cancer: an } \\
\text { exploratory study }\end{array}$ & 2000 & Canada & $\mathrm{CS}$ & $\begin{array}{l}\text { On-site } \\
\text { recruitment } \\
\text { (outpatient } \\
\text { clinic visit) }\end{array}$ & $\begin{array}{l}\text { One item scored on a 5-point Likert } \\
\text { item ('completely disagree' to } \\
\text { 'completely agree'): "I trust the } \\
\text { medical information I found on the } \\
\text { Internet." }\end{array}$ & $\begin{array}{l}\text { Nonprobability } \\
\text { sampling: } \\
\text { purposive sampling }\end{array}$ \\
\hline (Roach & Differences in & 2009 & USA & $\mathrm{CS}$ & Called via & One item scored on a 4-point item & Stratified sampling \\
\hline
\end{tabular}




\begin{tabular}{|c|c|c|c|c|c|c|c|}
\hline $\begin{array}{l}\text { et al. } \\
2009)\end{array}$ & $\begin{array}{l}\text { cancer } \\
\text { information- } \\
\text { seeking behavior, } \\
\text { preferences, and } \\
\text { awareness } \\
\text { between cancer } \\
\text { survivors and } \\
\text { healthy controls }\end{array}$ & & & & telephone & $\begin{array}{l}\text { format ('not at all' to 'a lot') to } \\
\text { "indicate how much they would trust } \\
\text { cancer information obtained from the } \\
\text { following sources" (i.e., internet). }\end{array}$ & $\begin{array}{l}\text { with oversampling } \\
\text { of minority groups }\end{array}$ \\
\hline $\begin{array}{l}\text { (Shea- } \\
\text { Budgell } \\
\text { et al. } \\
\text { 2014) }\end{array}$ & $\begin{array}{l}\text { Information needs } \\
\text { and sources of } \\
\text { information for } \\
\text { patients during } \\
\text { cancer follow-up }\end{array}$ & 2014 & Canada & $\mathrm{CS}$ & $\begin{array}{l}\text { On-site } \\
\text { recruitment } \\
\text { (outpatient } \\
\text { clinic visit) }\end{array}$ & $\begin{array}{l}\text { One item scored on a 4-point item } \\
\text { format ('not at all' to 'a lot' = 4) to } \\
\text { measure "the level of trust in } \\
\text { information sources" }\end{array}$ & $\begin{array}{l}\text { Nonprobability } \\
\text { sampling: } \\
\text { purposive sampling }\end{array}$ \\
\hline
\end{tabular}

3 Notes.

4 CS, Cross- sectional; NL, Netherlands.

5 a Number of particpants included in the study 
Table 2 (on next page)

Outcomes of the included studies. 
Table 2:

Outcomes of the included studies.

\begin{tabular}{|c|c|c|c|c|c|c|c|c|c|c|}
\hline \multirow[t]{2}{*}{ Study } & \multirow[t]{2}{*}{$\begin{array}{l}\text { Trust } \\
\text { a (m, } \\
\text { SD) }\end{array}$} & \multicolumn{5}{|c|}{ Sample characteristics } & \multicolumn{4}{|c|}{$\begin{array}{l}\text { Differences in trust between groups (MD, }[95 \% \mathrm{CI}] \\
\text { Cohen's d effect size) }\end{array}$} \\
\hline & & $\mathbf{N}^{\mathbf{b}}$ & $\begin{array}{l}\operatorname{Age} e^{c} \\
(\mathbf{m} / \mathbf{S D})\end{array}$ & Education & $\begin{array}{l}\text { Cancer } \\
\text { type }\end{array}$ & $\begin{array}{l}\text { Gender } \\
(\% \\
\text { female })\end{array}$ & $\begin{array}{l}\text { Female vs. } \\
\text { male } \\
\text { patients }\end{array}$ & $\begin{array}{l}\text { Highly vs. } \\
\text { low } \\
\text { educated }\end{array}$ & $\begin{array}{l}\text { Young vs. } \\
\text { old patients }\end{array}$ & $\begin{array}{l}\text { Cancer } \\
\text { types }\end{array}$ \\
\hline $\begin{array}{l}\text { (Crutze } \\
\text { n et al. } \\
2014)\end{array}$ & $\begin{array}{l}3.8 \\
(1.0)\end{array}$ & 45 & $53(12)$ & $\begin{array}{l}46 \% \text { high education; } 40 \% \\
\text { intermediate education; } 14 \% \\
\text { low education }\end{array}$ & NR & 76 & $\begin{array}{l}0.13,[-0.45 \\
0.71], \mathrm{d}= \\
0.14\end{array}$ & $\begin{array}{l}-0.58,[-1.64 \\
0.48], \mathrm{d}= \\
0.58\end{array}$ & NR & NR \\
\hline $\begin{array}{l}\text { (Loske } \\
\text { n et al. } \\
2005)\end{array}$ & $\begin{array}{l}4.3 \\
(1.0)\end{array}$ & 72 & $\begin{array}{l}50(30- \\
70)\end{array}$ & $\begin{array}{l}22 \% \text { graduate; } 43 \% \text { college; } \\
30 \% \text { some college, } 14 \% \\
\text { high school }\end{array}$ & $\begin{array}{l}\text { Breast } \\
\text { cancer } \\
\text { patients }\end{array}$ & 100 & NR & NR & NR & NR \\
\hline $\begin{array}{l}\text { (Lussie } \\
\text { z et al. } \\
2017 \text { ) }\end{array}$ & $\begin{array}{l}3.9 \\
(1.1)\end{array}$ & 192 & $\begin{array}{l}54(14- \\
86)\end{array}$ & NR & $\begin{array}{l}\text { Lung or } \\
\text { esophagea } \\
1 \text { cancer }\end{array}$ & 55 & NR & $\begin{array}{l}\text { High } \\
\text { educated } \\
\text { participants } \\
\text { reported } \\
\text { higher trust } \\
\text { scores }\end{array}$ & NR & NR \\
\hline $\begin{array}{l}\text { (Mayer } \\
\text { et al. } \\
2007 \text { ) }\end{array}$ & $\begin{array}{l}2.9 \\
(1.6)\end{array}$ & 597 & 58 & $\begin{array}{l}44 \% \text { more than high school; } \\
38 \% \text { high school; } 18 \% \text { less } \\
\text { than high school }\end{array}$ & $\begin{array}{l}18 \\
\text { different } \\
\text { cancer }^{\mathrm{d}} \\
\text { types }^{\mathrm{d}}\end{array}$ & 65 & NR & NR & NR & NR \\
\hline $\begin{array}{l}\text { (Pereira } \\
\text { et al. } \\
2000)\end{array}$ & $\begin{array}{l}3.5 \\
(0.6)\end{array}$ & 32 & 47 (9) & $\begin{array}{l}66 \% \text { college or university; } 34 \\
\% \text { junior or senior high } \\
\text { school }\end{array}$ & $\begin{array}{l}\text { Breast } \\
\text { cancer } \\
\text { patients }\end{array}$ & 100 & NR & NR & NR & NR \\
\hline $\begin{array}{l}\text { (Roach } \\
\text { et al. } \\
\text { 2009) }\end{array}$ & $\begin{array}{l}3.0 \\
(1.6)\end{array}$ & 692 & NR & NR & $\begin{array}{l}\text { Different } \\
\text { cancer } \\
\text { types }\end{array}$ & NR & NR & NR & NR & NR \\
\hline $\begin{array}{l}\text { (Shea- } \\
\text { Budgell }\end{array}$ & $\begin{array}{l}3.1 \\
(1.2)\end{array}$ & 411 & NR & $\begin{array}{l}33 \% \text { high school or less; } 21 \\
\% \text { post-high school; } 33 \%\end{array}$ & $\begin{array}{l}\text { Seven } \\
\text { different }\end{array}$ & 53 & NR & NR & NR & $\begin{array}{l}\text { No } \\
\text { significan }\end{array}$ \\
\hline
\end{tabular}


3 Notes.

\begin{tabular}{|l|l|l|l|l|l|l|l|l|}
\hline $\begin{array}{l}\text { et al. } \\
\text { 2014) }\end{array}$ & & & $\begin{array}{l}\text { college or university; } 10 \% \\
\text { postgraduate; } 4 \% \text { not } \\
\text { specified }\end{array}$ & $\begin{array}{l}\text { types/grou } \\
\text { p of } \\
\text { cancer } \\
\text { types } \\
\text { reported }\end{array}$ & $\begin{array}{l}\text { associatio } \\
\text { ns } \\
\text { between } \\
\text { cancer site } \\
\text { and level } \\
\text { of trust }\end{array}$ \\
\hline
\end{tabular}

4 m, mean; SD, standard deviation; MD, mean difference; NR, not reported;

5 a Average trust in online information reported on a 5-point item format.

6 b The number participating of cancer patients.

$7 \quad{ }^{\mathrm{c}}$ Age reported in years.

$8 \quad{ }^{\mathrm{d}}$ Breast and cervical were most frequent reported types of cancer.

$9 \quad$ e The most common initial diagnoses were gynecologic, non-melanoma skin, and breast cancers. 
Table 3 (on next page)

Risk of bias appraisal using the RTI item bank. 


\section{Table 3:}

2 Risk of bias appraisal using the RTI item bank.

\begin{tabular}{|c|c|c|c|c|c|c|c|}
\hline \multirow[t]{2}{*}{ Study } & \multicolumn{3}{|c|}{ Selection bias/confounding } & \multirow{2}{*}{$\begin{array}{l}\text { Detection } \\
\text { bias }\end{array}$} & \multirow{2}{*}{$\begin{array}{l}\text { Selective } \\
\text { outcome } \\
\text { reporting }\end{array}$} & \multirow{2}{*}{$\begin{array}{l}\text { Confounding } \\
\text { Q11: }\end{array}$} & \multirow{2}{*}{$\begin{array}{l}\text { Overall } \\
\text { Assessment } \\
\text { Q13: }\end{array}$} \\
\hline & Q1 & Q2 & Q3 & & & & \\
\hline $\begin{array}{l}\text { (Crutzen } \\
\text { et al. } \\
2014)\end{array}$ & NR & No & NA & Yes & No & Yes & No \\
\hline $\begin{array}{l}\text { (Losken } \\
\text { et al. } \\
2005)\end{array}$ & No & No & NA & No & No & Yes & Yes \\
\hline $\begin{array}{l}\text { (Lussiez } \\
\text { et al. } \\
2015)\end{array}$ & NR & No & NA & No & No & Yes & No \\
\hline $\begin{array}{l}\text { (Mayer } \\
\text { et al. } \\
2007)\end{array}$ & NR & No & NA & Yes & No & Yes & No \\
\hline $\begin{array}{l}\text { (Pereira } \\
\text { et al. } \\
2000)\end{array}$ & No & No & NA & No & No & Yes & No \\
\hline $\begin{array}{l}\text { (Roach } \\
\text { et al. } \\
2009 \text { ) }\end{array}$ & NR & No & NA & Yes & No & Yes & No \\
\hline $\begin{array}{l}\text { (Shea- } \\
\text { Budgell } \\
\text { et al. } \\
2014 \text { ) }\end{array}$ & No & No & NA & NR & No & Yes & Partially \\
\hline
\end{tabular}

3 Notes.

4 Q1, Do the inclusion criteria vary across the participants of the study?; Q2, Does the strategy for

5 recruiting participants into the study differ?; Q3, Is the selection of the comparison group

6 inappropriate?; Q6, Were valid and reliable measures used?; Q9, Are any important primary

7 outcomes missing from the results; Q11, Are results believable taking study limitations into

8 consideration?; Q13, Were the important confounding variables taken into account in the

9 design?; NR, not reported; NA, not applicable. 